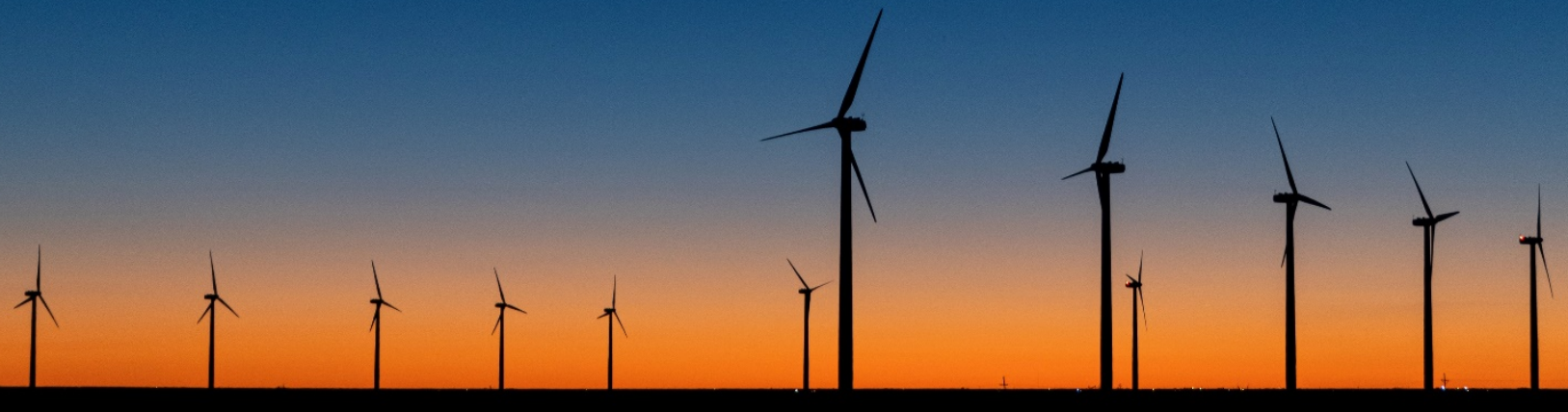

\title{
Wind Turbine Drivetrain Reliability and Wind Plant Operations and Maintenance Research and Development Opportunities
}

Jonathan Keller, ${ }^{1}$ Shawn Sheng, ${ }^{1}$ Yi Guo, ${ }^{1}$ Benjamin Gould, ${ }^{2}$ and Aaron Greco ${ }^{2}$

1 National Renewable Energy Laboratory

2 Argonne National Laboratory

NREL is a national laboratory of the U.S. Department of Energy Office of Energy Efficiency \& Renewable Energy

Operated by the Alliance for Sustainable Energy, LLC

This report is available at no cost from the National Renewable Energy Laboratory (NREL) at www.nrel.gov/publications.
Technical Report

NREL/TP-5000-80195

September 2021 


\title{
GNREL
}

\section{Wind Turbine Drivetrain Reliability and Wind Plant Operations and Maintenance Research and Development Opportunities}

\author{
Jonathan Keller, ${ }^{1}$ Shawn Sheng, ${ }^{1}$ Yi Guo, ${ }^{1}$ Benjamin Gould, ${ }^{2}$ \\ and Aaron Greco ${ }^{2}$
}

\section{National Renewable Energy Laboratory \\ 2 Argonne National Laboratory}

\section{Suggested Citation}

Keller, Jonathan, Shawn Sheng, Yi Guo, Benjamin Gould, and Aaron Greco. 2021. Wind Turbine Drivetrain Reliability and Wind Plant Operations and Maintenance

Research and Development Opportunities. Golden, CO: National Renewable Energy Laboratory. NREL/TP-5000-80195. https://nrel.gov/docs/fy21osti/80195.pdf.

NREL is a national laboratory of the U.S. Department of Energy Office of Energy Efficiency \& Renewable Energy Operated by the Alliance for Sustainable Energy, LLC

This report is available at no cost from the National Renewable Energy Laboratory (NREL) at www.nrel.gov/publications.

Contract No. DE-AC36-08GO28308
Technical Report

NREL/TP-5000-80195

September 2021

National Renewable Energy Laboratory 15013 Denver West Parkway Golden, CO 80401

303-275-3000 • www.nrel.gov 


\section{NOTICE}

This work was authored in part by the National Renewable Energy Laboratory, operated by Alliance for Sustainable Energy, LLC, for the U.S. Department of Energy (DOE) under Contract No. DE-AC36-08GO28308. Funding provided by the U.S. Department of Energy Office of Energy Efficiency and Renewable Energy Wind Energy Technologies Office. The views expressed herein do not necessarily represent the views of the DOE or the U.S. Government.

This report is available at no cost from the National Renewable Energy Laboratory (NREL) at www.nrel.gov/publications.

U.S. Department of Energy (DOE) reports produced after 1991 and a growing number of pre-1991 documents are available free via www.OSTI.gov.

Cover Photo by Werner Slocum: NREL 62958.

NREL prints on paper that contains recycled content. 


\section{Preface}

The Drivetrain Reliability Collaborative holds annual meetings convened by the National Renewable Energy Laboratory, Argonne National Laboratory, and the U.S. Department of Energy to bring together researchers and stakeholders throughout the wind turbine drivetrain supply, operations, and sustainment chain. A prime focus of these meetings is to explore the state of the art in mechanical system reliability as well as operations and maintenance challenges that, if solved, could deliver significant benefits.

The last in-person meeting was held in Golden, Colorado from Feb. 18-19, 2020. More than 150 attendees participated, representing industry, academia, other research laboratories, and government. The two-day program included podium presentations covering a broad range of topics including gearbox and main bearing design and modeling, drivetrain condition monitoring, and wind plant operations and maintenance and data analytics. Panel discussions were held on topics such as land-based and offshore wind turbine drivetrain reliability, wind plant operations and maintenance challenges, and artificial intelligence, machine learning, and "big data" analytics opportunities. More recently, the Collaborative held a webinar on Feb. 1617, 2021. Of more than 350 registrants, approximately $75 \%$ were from industry. This report summarizes the research and development opportunities identified from these most recent meetings.

The presentations from all of the past annual Drivetrain Reliability Collaborative meetings are available at https://app.box.com/s/095z4ly60gvwrxv71hbg32skwrjk1q9q. 


\section{Acknowledgments}

This work was authored in part by the National Renewable Energy Laboratory, operated by Alliance for Sustainable Energy, LLC, under Contract No. DE-AC36-08GO28308 and Argonne National Laboratory, operated by the University of Chicago, under contract No. DE-AC0206CH11357 for the U.S. Department of Energy. Funding provided by the U.S. Department of Energy Office of Energy Efficiency and Renewable Energy Wind Energy Technologies Office. The authors would also like to thank Heather Doane and Alexsandra Lemke for assistance in organizing and facilitating the workshops. 


\section{List of Acronyms}

AI

AGMA

ANL

ANSI

BD

DIN

DOE

DRC

IEC

ISO

LCOE

ML

NREL

O\&M

OpEx

PHM

R\&D

RUL

SCADA

TS

WEC artificial intelligence

American Gear Manufacturers Association

Argonne National Laboratory

American National Standards Institute

big data

Deutsches Institut für Normung

Department of Energy

Drivetrain Reliability Collaborative

International Electrotechnical Commission

International Organization for Standardization

levelized cost of energy

machine learning

National Renewable Energy Laboratory

operations and maintenance

operational expenditure

prognostics and health management

research and development

remaining useful life

supervisory control and data acquisition

technical specification

white-etching crack 


\section{Table of Contents}

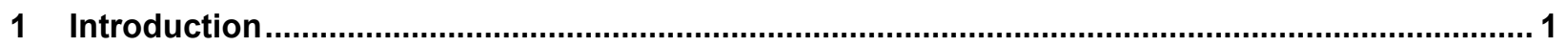

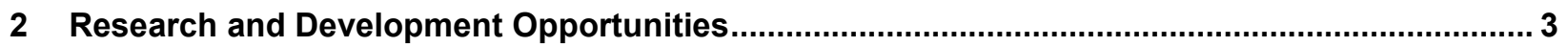

2.1 Improving Drivetrain Reliability Through Materials and Design .......................................... 3

2.1.1 Failure Mode Characterization and Design Life Calculation......................................... 4

2.1.2 Novel Material and Lubricant Development................................................................ 7

2.2 Improving Wind Turbine Availability Through Data Analytics ................................................ 7

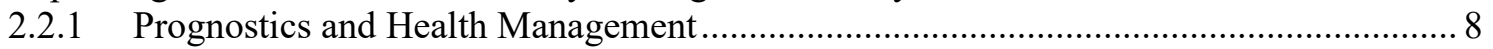

2.2.2 Operations and Maintenance Optimization..................................................... 9

2.2.3 Artificial Intelligence, Machine Learning, and Big Data Analytics................................ 9

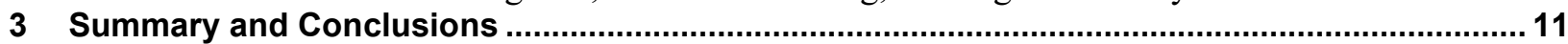

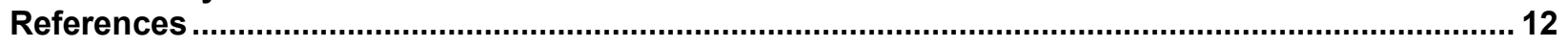

\section{List of Figures}

Figure 1. Drivetrain reliability research process 


\section{Introduction}

The wind energy industry has seen tremendous growth over the past two decades with a cumulative installed capacity reaching 651 gigawatts globally and 105 gigawatts in the United States at the end of 2019 (Lee and Zhao 2020). The cost of energy from wind has declined during the past two decades (U.S. Department of Energy [DOE] 2015) due to a combination of lower capital costs, higher production, and more efficient operation. Wind power plant operational expenditures (OpEx), however, remain an appreciable contributor to the overall cost of wind energy, with a capacity-weighted average cost of $\$ 44$ per kilowatt per year $(\$ 12$ per megawatt-hour) for land-based wind plants commissioned between 2015 and 2018 in the United States (Wiser, Bolinger, and Lantz 2019).

OpEx represents a sizable and potentially growing share of the levelized cost of energy (LCOE), especially as wind's LCOE declines because of lower upfront costs and better performance. Recent data suggests wind plant OpEx can account for 25\% to more than $35 \%$ of the LCOE of both land-based and offshore wind (Wiser, Bolinger, and Lantz 2019; Lantz 2013; Carroll et al. 2017). Approximately half of land-based plant OpEx costs are associated directly with turbine operations and maintenance (O\&M) (Wiser, Bolinger, and Lantz; Lantz 2013). Turbine O\&M costs therefore represent the single largest component of wind plant OpEx and the primary source of potential O\&M cost reductions, with total OpEx cost reductions possibly contributing $10 \%$ or more of the expected reduction in land-based wind LCOE (Wiser, Bolinger, and Lantz; Stehly, Beiter, and Duffy 2020) and as much as $40 \%$ of the expected reduction for fixed-bottom, offshore wind plants if improved vessel accessibility and remote maintenance strategies are included (Stehly, Beiter, and Duffy 2020). Although comparable information in the literature for existing offshore wind plants is sparse, it indicates that pitch system failure rates can be over 2 times higher offshore than onshore. Failures of the main bearings, gearbox and generator, along with the blades, are the highest contributors to downtime for both offshore and onshore turbines (Dao, Kazemtabrizi, and Crabtree 2019); unsurprisingly, OpEx costs are approximately one-anda-half to three times higher (Dao, Kazemtabrizi, and Crabtree 2019; Stehly, Beiter, and Duffy 2020) for offshore as compared to onshore wind plants.

The Drivetrain Reliability Collaborative (DRC), a consortium led by National Renewable Energy Laboratory (NREL) and Argonne National Laboratory (ANL) through the support of the DOE Wind Energy Technologies Office, conducts research and development (R\&D) in this area. The DRC has evolved from its beginnings as the Gearbox Reliability Collaborative (Keller 2014) by expanding its scope to include other important drivetrain components such as pitch, main shaft, and generator bearings; tribology and surface engineering (Greco 2014); and technologies related to O\&M such as condition monitoring, prognostics and health management, remaining useful life (RUL) estimation, and data analytics (Sheng 2014a). The DRC process for R\&D is described in Figure 1. Once a prevalent, costly, and uncharacterized failure is identified, it is first characterized through benchtop testing in which the most significant contributors to the failure are quantified. A design life calculation can then be established, and after development of fullscale models, verified through comparison to failure statistics. Ideally, the design life model can then be used to improve designs via integration into American Wind Energy Association recommended practices and International Electrotechnical Commission (IEC) and American Gear Manufacturers Association (AGMA) design standards, as well as for prognostics and 
optimization of O\&M. This work supports both the offshore and land-based tall wind R\&D priorities identified in the recently published DOE Wind Energy Technologies Office Multi-Year Program Plan (DOE 2020).

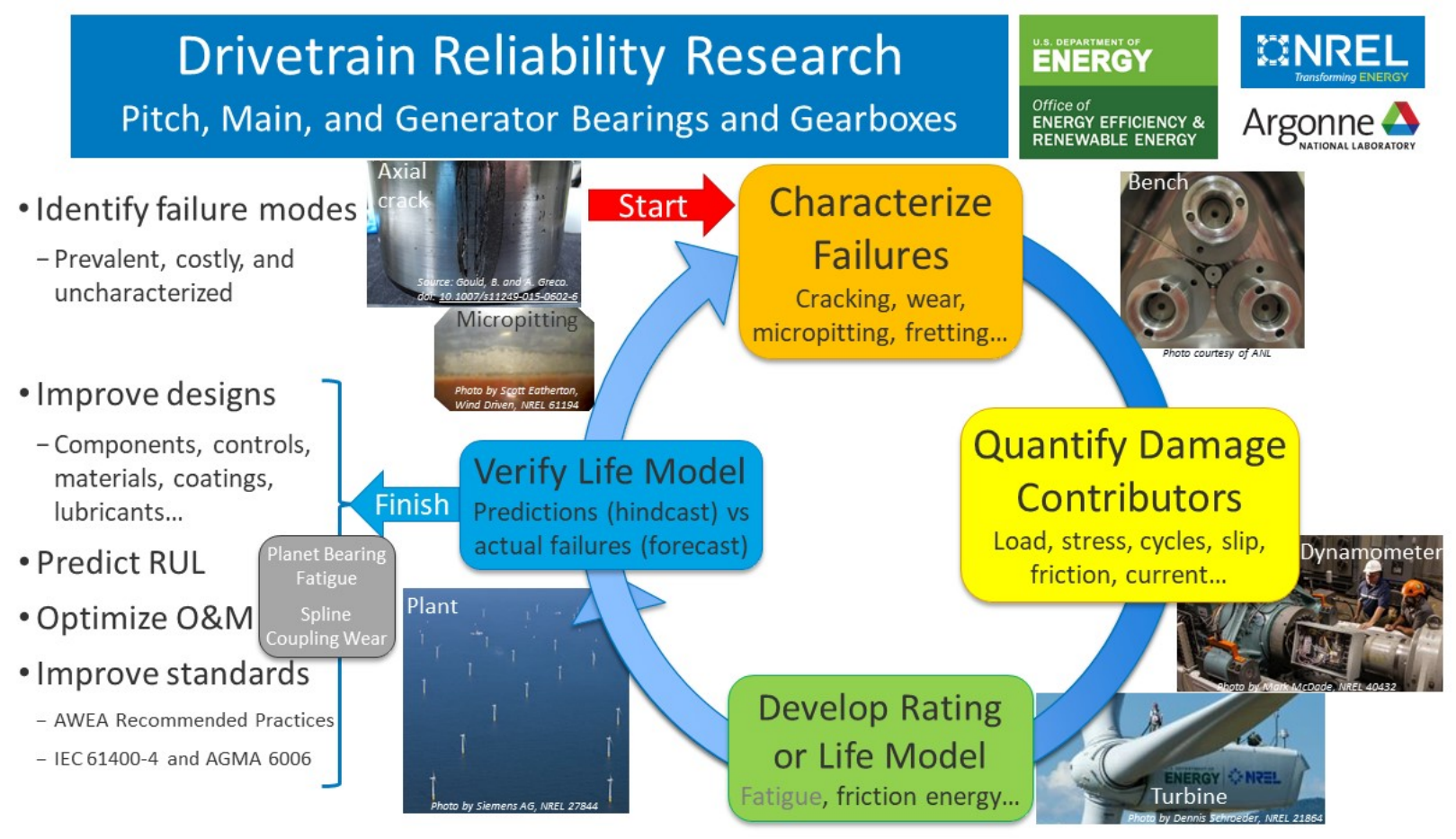

Figure 1. Drivetrain reliability research process

In addition to leading focused R\&D projects (Keller 2017; Keller 2019), the DRC hosts focused seminars (Sheng 2010; Errichello et al. 2012; ANL 2014) and annual meetings (NREL 2021) to bring researchers and stakeholders throughout the drivetrain supply chain together to exchange information on the latest R\&D, operational challenges, and future opportunities. The DRC meetings typically feature a two-day program that includes presentations covering a broad range of topics such as tribology, gearbox and main bearing design, verification and modeling, drivetrain condition monitoring, wind plant O\&M, and data analytics, as well as facilitated panel discussions. Recent panel discussions included land-based and offshore wind drivetrain reliability and wind plant O\&M challenges, and the state of the art in artificial intelligence (AI), machine learning (ML), and "big data" (BD) analytics in the wind industry. The R\&D opportunities identified at the most recent DRC meetings are discussed and summarized in this report, which serves as an update to a similar prior report developed by Keller et al. (2016). 


\section{Research and Development Opportunities}

Pitch bearings, main bearings, and gearboxes in conventional wind turbine drivetrains often do not meet their 20-year minimum specified lifetime, primarily due to premature bearing failures (Kotzalas and Doll 2010; Brake 2013; Hart et al. 2019; Greco et al. 2013; Veers et al. 2018) that result in turbine downtime as well as expensive, time-consuming repairs or replacements often necessitating the deployment of large lifting cranes. The dominant failure modes of the drivetrain components and the conditions that lead to their failure are not fully accounted for during product design or routinely modeled for life management. Drivetrain reliability improvements and O\&M cost reductions remain top priorities for both land-based and offshore wind turbines, especially as wind turbines continue to be deployed in increasingly remote and offshore locations, continue to increase in size, and are becoming expected to be in service beyond their original design life-all of which correspond to an increase in the impact of any reliability issues on O\&M costs. All aspects of the drivetrain life cycle, from standards to materials and design, to manufacturing, O\&M, and decommissioning or repowering, are impacted.

\subsection{Improving Drivetrain Reliability Through Materials and Design}

The objective of this area of work is innovation to enable more reliable drivetrain designs by optimizing the performance and reliability of the mechanical design and the materials used therein, while decreasing the LCOE. Recently, the interaction of reliability, energy production, and the LCOE with the wind plant layout has even been investigated (Clark et al. 2021). Reliability is the probability that a product will not fail during a defined period of time under given functional and surrounding conditions. The term probability takes into consideration that various failure events can be caused by coincidental, stochastic distributed causes and that the probability can only be described quantitatively (Bertsche 2008).

Wind turbine gearboxes used in horizontal axis wind turbine drivetrains continue to grow in size to up to three meters in diameter, power up to $15 \mathrm{MW}$, and torque-density of 200 newton-meters per kilogram (Vaes, Clement, and Lindstedt 2021; Daners and Nickel 2021; ZF 2021; Winergy 2021; Nejad et al. 2021). They are designed for a minimum 20-year design life as specified in the IEC 61400-4 and AGMA 6006 gearbox design standards. With up to four stages and a speed increasing ratio of up to 200 , the gearbox is a system comprising many elements (primarily the rotating shafts, gears, bearings), so the reliability of the gearbox is the product of the reliability of all the failure modes for which there exists a reliability calculation. However, many-if not most - of the failure modes experienced in operation do not have a standardized reliability calculation; hence, as described earlier, there exists a difference between the apparent reliability observed in operation and the calculated design reference reliability. This is not unusual and occurs in other industries (Cunningham and Morgan 1979; Zaretsky and Branzai 2017), although the O\&M cost impact for wind turbines can be more apparent.

As described in Verband Deutscher Maschinen- und Anlagenbau 23904 and IEC Technical Specification (TS) 61400-4-1 the gearbox reliability calculation considers gear tooth surface durability (pitting) according to the International Organization for Standardization (ISO) standard 6336-2 and bending strength according to ISO standard 6336-3; rolling element bearing rating life from subsurface-initiated fatigue (i.e., rolling contact fatigue) according to ISO standard 281 and ISO/TS 16281; and shaft fatigue fracture according to Deutsches Institut für Normung (DIN) 743 and American National Standards Institute (ANSI)/AGMA 6001. In some 
cases, a safety factor for or percent risk of these failure modes can at least be quantified in the gearbox design process, including for gear tooth scuffing (using ISO/TS 6336-20, ANSI/AGMA 925, and ISO/TS 6336-21) and for and gear tooth micropitting (using ISO/TS 6336-22), or otherwise assessed for gear tooth flank fracture according to ISO/TS 63364. Safety factors for the static strength of gears and bearings are calculated according to ISO 6336 and ISO 76, respectively. Other bearing failure modes, such as surface-initiated fatigue (e.g., micropitting), adhesive wear, corrosion, electrical damage, and white-etching cracks (WECs) can only be assessed qualitatively. Requirements for materials, processing, and manufacture are part of these standards. Design guidance for the use of plain bearings in the gearbox is under development as they offer advantages in terms of torque-density and are only life-limited by wear, although they are already becoming common in new gearboxes (Erdman and Keller 2016; Weber and Hansen 2021; Zeichfüß1 et al. 2021).

Main bearings and generator bearings, including those used in direct-drive turbines, do not have an application-specific design standard and are typically designed with respect to ISO 76, ISO 281, and ISO/TS 16281. Because pitch bearings are not under constant rotation, ISO/TS 16281 is used as a design specification and requires detailed simulations of the bearing to be sufficiently precise. Other life calculation methods have been proposed for oscillatory applications (Houpert 1999; Wöll, Jacobs, and Kramer 2018), including guidance to prevent fretting corrosion and false brinelling.

The aforementioned discussion specifies documentation in terms of standards and technical specifications. An international standard provides rules, guidelines, or characteristics for activities or for their results, aimed at achieving the optimum degree of order in a given context. A technical specification addresses work still under technical development, or where it is believed that there will be a future, but not immediate, possibility of agreement on an international standard. A technical specification is published for immediate use, but it also provides a means to obtain feedback. The aim is that it will eventually be transformed and republished as an international standard. A final category is a technical report, which may include data obtained from a survey, for example, or from an informative report, or information about the perceived "state of the art" (ISO 2021).

\subsubsection{Failure Mode Characterization and Design Life Calculation}

As described in the previous section, there are challenges for existing design methods to produce components that are reliable for the 20 -year or higher lifetime of wind energy plants. It is not a coincidence that the failure modes that are not currently characterized with a standardized reliability calculation are also the ones that are most prevalent in wind turbine drivetrains. An early attempt at developing design life calculations was undertaken for yaw and pitch bearings by Harris, Rumbarger, and Butterfield (2009). Failure modes related to load-sharing in planetary shaft bearings (LaCava et al. 2013; Guo, Keller, and Parker 2014; Guo, Keller, and LaCava 2015; Keller and Wallen 2015; Keller et al. 2018; Guo and Keller 2020) and high-speed shaft bearings (Helsen et al. 2016; Guo and Keller 2018; Helsen, Guo, and Keller 2018) and rating of splined gear-couplings (Guo et al. 2016) were investigated in early DRC efforts from 2010 to 2017. Significant research has also been devoted to characterizing bearing WEC failures starting in 2017 (Keller, Gould, and A. Greco. 2017). The following sections summarize the state of the art and new opportunities in R\&D identified at the recent DRC meetings for the most prevalent failure modes in drivetrain components. 


\subsubsection{Pitch Bearing Fatigue, Wear, and Frictional Corrosion}

Slew ring or "pitch" bearings are used in wind turbines to connect the blade root to the hub and support the resulting simultaneous radial, axial, and overturning moment loads. Although not identified as large a source of reliability issues as gearboxes and main bearings in the first DRC workshop report (Keller et al. 2016), there has been an increasing level of industry interest in pitch bearing reliability with some populations demonstrating a $12 \%$ failure rate in 20 years (Hornemann 2019). Further, pitch system failure rates in some populations are over 2 times higher offshore than onshore (Dao, Kazemtabrizi, and Crabtree 2019). These bearings are usually grease-lubricated, large in diameter, and thin in cross section, making them vulnerable to deflections and consequent stress concentrations, a trend which will continue as rotor diameters increase even more for tall land-based and offshore wind turbines. With the introduction of advanced controllers and an accompanying increase in pitch activity, the total pitch travel of these bearings has increased tremendously. For these reasons, there is an increased need to study rolling element and raceway curvatures, deformations, misalignment, sliding, and skewing, load distributions, contact stresses, edge loading, and lubrication conditions more accurately to understand pitch bearing failures. This includes fatigue and wear-related failures and frictional corrosion (i.e., false brinelling and fretting corrosion [Kotzalas and Doll 2010, Errichello 2004, Grebe et al. 2018]) failures, as described in ISO 15243 but not accounted for in ISO 281 or ISO/TS 16281. The most pertinent research questions are:

- How should the design life of pitch bearings be calculated, when the typical bearing fatigue life standards are not applicable?

- How can different pitch bearing concepts be evaluated?

- Can premature pitch bearing failures be mitigated through design modifications and control strategies without derating?

- How do large blades, advanced control strategies, wake effects, offshore dynamic loading and environmental conditions, and plant layout (Clark 2021) influence pitch bearing reliability?

If successful, this work will enable the design and specification of more reliable pitch bearings, a key concern in the long-term operation of onshore wind turbines and new development of offshore wind turbines. The research should include benchtop, scaled, and/or even full-scale experimental investigations of existing and innovative designs along with collection of failure data, modeling and analysis conducted in a systematic fashion (Han et al. 2015; Becker et al. 2017; Schwack, Prigge, and Poll 2018; Stammler, Reuter, and Poll 2018; Fischer and Mönnig 2019; Brinji, Fallahnezhad, and Meehan 2020; Stammler et al. 2020; Menck, Stammler, and Schleich 2020; Schwack et al. 2020; Song and Karikari-Boateng 2021) similar to how the DRC is already approaching main and gearbox bearing reliability $\mathrm{R} \& \mathrm{D}$.

\subsubsection{Main Bearing Wear}

Main shaft roller bearing failure modes include progressive wear, fretting, smearing, WECs, and spalling (Keller et al. 2016; Kotzalas and Doll 2010; Brake 2013; Hart et al. 2019; Greco et al. 2013; Hart et al. 2020). Specifically highlighted in many works is the importance of progressive wear, which is not accounted for in the current design process, of the spherical roller bearing typically used as the main bearing in three-point mounted drivetrains. Failure rates in some populations can be as high as $20 \%-30 \%$ in as little as 6-10 years (Brake 2013; Hart et al. 2019); however, other populations can be very reliable. Bearing fatigue life standards are reaching their 
limit for calculating main bearing rating life due to low operational speeds, high axial loads, and lubrication characteristics, especially as tall land-based and offshore turbines continue to increase in size. These types of failures can be better understood through both accelerated benchtop as well as full-scale investigations supported by modeling (Sethuraman, Guo, and Sheng 2015; Stirling, Hart, and Kazemi Amiri 2021; Guo et al 2021). The aim of this work should be to help identify root causes and make better-informed initial design and maintenance decisions (Keller et al. 2016). Some pertinent research questions are:

- What are the key differences between more reliable and less reliable main bearing populations?

- How valid are current design life calculation methodologies?

- What are the benefits and limitations of different mounting configurations and bearing types and sizes, especially for offshore geared and direct-drive turbines (Lucas 2019)?

- Can premature main bearing failures be mitigated through design changes and control strategies without derating?

- How do advanced control strategies, wake effects, offshore dynamic loading and environmental conditions, and plant layout (Clark 2021) influence main bearing reliability?

- What impacts do roller slip and stray current have on the formation of WECs and main bearing failures?

\subsubsection{Gearbox Bearing White-Etching Cracks}

The most common gearbox failure mode historically has been attributed to WECs in bearings, which refer to the appearance of the bearing steel microstructure when a cross section is polished, etched with chemicals, and examined under reflected light. WECs can often propagate to spalls or lead to a complete splitting of the inner ring after as little as 5\%-20\% of the predicted design life (Greco et al 2013). Although the O\&M cost impact of WECs within the gearbox has been reduced by the advent of uptower repairs, mitigating or resolving WEC-related bearing failures is still important (Keller et al. 2016; Guo and Keller 2020). The main drivers for the creation of WECs in steel specimens have been identified and verified at the material level (Gould and Greco 2015; Evans 2016; Gould and Greco 2016; Gould, Greco, Stadler, and Xiao 2017; Gould, Greco, Stadler, and Vegter et al. 2017; Manieri et al. 2019; López-Uruñuela et al. 2021). However, in a full-scale wind turbine gearbox, the conditions leading to WECs, the process by which the failure culminates, and the reasons for their apparent prevalence are still not fully understood (Vaes et al. 2019). The importance of steel microstructure, heat treatment, lubricant composition, and electrical current is also becoming more understood (Ščepanskis, Gould, and Greco 2017; Gould, Demas, and Greco 2019; Gould and Paladugu et al. 2019; Gould and Demas et al. 2019; Roy et al. 2019; Gould et al. 2021). Recent evidence does indicate bearing failures due to WECs can be reduced through implementation of several countermeasures (Jensen, Heuser, and Petersen 2021); however, design life calculations are still under development and require further verification (Guo et al. 2020; Leung, Voothaluru, and Neu 2021; Natarajan et al. 2021). Pertinent research questions are:

- Can a sufficiently accurate design life calculation for WECs be developed?

- What is the importance of transient turbine operations that induce short-term, high loads for WECs?

- How much does the lubricant heater and cooler influence bearing slip and WEC formation? 
- Do low-load curtailment operations contribute to WECs?

- What is the relative importance of tribological and material effects such as heat treatment, lubricant viscosity, surface engineering, water content in oil, and stray electrical current?

\subsubsection{Plain Bearing Wear}

As described earlier, plain bearings are already becoming common in new gearbox designs (Erdman and Keller 2016; Weber and Hansen 2021; Zeichfüß1 et al. 2021) as they offer advantages in terms of cost, torque-density, and calculated design life and they only limited by wear rather than determined by load-dependent rolling contact fatigue. Plain bearings are reliable when operating within the hydrodynamic lubrication regime and pressure and temperature limits. However, they are susceptible to failure during operational conditions when high loads are combined with low speed and/or inadequate lubrication. Although design guidance for plain bearings is under development for the IEC 61400-4 gearbox design standard, the wear rate is difficult to predict accurately in the most challenging operational conditions. Additionally, innovative plain bearing designs have also been investigated for use in the main bearing position (Rolink et al. 2021). Pertinent research questions are:

- What are the challenges for plain bearings when used in the gearbox or as a main bearing?

- How can wear rates be more accurately predicted?

- What lubricants and journal bearing materials are best for wind turbines?

\subsubsection{Novel Material and Lubricant Development}

There is a complementary need to investigate the impacts of the component material, surface engineering, and lubricant composition on reliability for each of the failure modes discussed in the previous section (McGuire 2021). For example:

- What lubricant and additive package characteristics are optimal for bearings and gears at different locations in the drivetrain?

- How do various lubricant compositions, additives, and conditions affect these failure modes (Schwack et al. 2020)?

- In terms of bearing or gear materials and surface engineering, what material innovations related to both the bulk material and coatings are necessary to address the dominant failure modes? How can materials, surface engineering, and additive manufacturing support continued improvement in torque density and reliability?

- How can the service life of lubricants be extended? How can lubricants be recycled or reconditioned and reused (SKF 2021)?

\subsection{Improving Wind Turbine Availability Through Data Analytics}

Much of the early work conducted by the DRC related to condition monitoring and the diagnosis of drivetrain faults (Hong, Dhupia, and Sheng 2014a; Yan et al. 2014; Dempsey and Sheng 2013) using gearbox fault data gathered during dynamometer testing (Dempsey and Sheng; Zappala et al. 2014; Yampikulsakul et al. 2014; Sheng 2014b; Sheng 2014c; Hong et al. 2017; Mauricio, Sheng, and Gryllias 2020). Recently, monitoring of gearbox oil debris through analysis of the filter elements was also completed (Sheng and Roberts 2017). As the industry has started recognizing the benefits of condition monitoring and prognostics, related R\&D has been launched in the areas of supervisory control and data acquisition (SCADA)-based modeling for 
gearbox fault detection and prediction (Orozco, Sheng, and Phillips 2018; Williams et al. 2020; Desai et al. 2020), and physics domain modeling with inputs from the data domain for component RUL prediction (Guo et al 2020). A prognostics and health management (PHM) framework for wind turbines was also introduced, which highlighted RUL as the expected output and described the integration of data and physics domain modeling methods (Sheng and Guo 2019). It provides a systematic view of possible avenues of $R \& D$ for the wind industry to benefit from PHM technologies.

Managing wind plants with multiple turbine types is challenging because failure modes and rates can vary by turbine type and component manufacturer and model. The methodologies for wind plant management, therefore, must consider such scenarios and be scalable and transferrable. Increased data sharing between owners and original equipment manufacturers has led to longer component service life; however, comprehensive and consistent data that includes predictive time series and failure records is needed. The data should be made available to enable broad R\&D collaborations across all stakeholders in a manner such that they are securely protected, quality controlled (e.g., about $20 \%$ to $30 \%$ of electricity outage information can sometimes be missing), and transparent.

Digital technologies have improved O\&M (Reininga 2020; Doner 2020); however, there are still a lot of R\&D needs to harness their full potential (Guo et al. 2020; Gao and Sheng 2018; Verstraeten et al. 2019; Pfaffel, Faulstich, and Sheng 2019). With the emphasis of an AI-focused R\&D initiative within DOE (2021), it would be beneficial to examine the following:

- How may digital technologies benefit drivetrain reliability and wind plant O\&M?

- What gaps exist?

- What roles can the DOE Wind Energy Technology Office and its laboratories play?

These opportunities are described in the following sections.

\subsubsection{Prognostics and Health Management}

Opportunities with PHM technologies range from sensing to signal processing, modeling, and decision making for both electrical and mechanical components. New sensor technologies could be required to effectively measure the physical characteristics of bearing failures, such as in pitch systems. A relevant research question is:

- With the boom in new technologies related to the Internet of Things and digitalization, how can the wind sector benefit and add more "intelligence" to future wind plants?

An example is the benefits that can be achieved by combining a high-rate gearbox torque sensor and onboard analytics to determine gearbox RUL and optimize power production (Doner 2020).

Prognostics, or more specifically, the prediction of component RUL (Guo et al. 2020), should be one of the focused areas of R\&D based on BD analytics, ML, data fusion, cloud computing, and mass storage. One example of the integration of these technologies is the application of deep learning for automated gear and bearing borescope or failure analysis damage image classification. One R\&D challenge is: 
- How can credible component RUL predictions account for different failure modes (e.g., surface and subsurface failures)?

Often this is accomplished through a combination of physics and data domain models. These models are expected to provide a reliable evaluation and prediction of component health at any given time in the component's expected life cycle. They are not only valuable to achieve preventive or smart maintenance, but also for life extension of aging turbine drivetrain components. PHM is a balancing act between determining an appropriate lead time for maintenance actions and an acceptable confidence level because the cost of the maintenance action typically increases as the lead time decreases.

Inspired by the biological immune and nervous systems and a further advance beyond PHM, engineering immune systems (EISs) attempt to avoid failures and large disturbances instead of compensating by applying traditional control or recovering the system by physical maintenance (Lee, Ghaffari, and Elmeligy 2011). With EISs, wind turbines will have the capability to learn and respond to unseen events, adaptability to retain memory to facilitate responses, and autonomy for self-controlled ability. EISs have potential to be a significant turning point for wind plant O\&M to achieve resilient and self-maintaining wind turbines of the future.

\subsubsection{Operations and Maintenance Optimization}

There is an opportunity to develop tools that can help optimize wind plant O\&M strategies for faulted components to minimize downtime and cost. Such optimizations ideally will consider the component design, site conditions, age, and expected RUL. For offshore wind plants, it is also critical to consider maintenance logistics, such as vessel availability and site accessibility based on wind, wave, and icing conditions. Economic analyses for different operational scenarios, such as derating, could also be included with maximation of profit per energy produced as a new optimization objective. The tools should recommend when it is most economical to conduct maintenance and enable evaluation of different economic scenarios. Essential questions influencing the economic analysis are:

- When can a component be reasonably considered at the end of its life?

- Can advances in robotics and drone technology be economically leveraged to optimize maintenance (Rinaldi, Thies, and Johanning 2021)?

The effectiveness of these tools could also benefit from advanced data analytics or computational techniques. The concept of uncertainty in the realm of reliability is not very well accepted by the wind industry. There is a need to research uncertainty characterization, aggregation, and propagation. Questions include:

- How does reliability impact performance?

- How can uncertainty be incorporated in the O\&M strategy optimization?

\subsubsection{Artificial Intelligence, Machine Learning, and Big Data Analytics}

As briefly described in the previous sections, digital technologies including AI, ML, and BD techniques can play a vital role in PHM and O\&M optimization for wind. Traditional approaches suffer from expensive model tuning, inefficiency in handling an overwhelming amount of data, and limitations in achievable accuracy even with increasing scale (i.e., data size and model size). 
AI, ML, and BD analytics technologies enable effective and efficient handling of the large volumes and various types of data seen in the wind industry. However, AI models often are not supported by solid physical understanding of the modeled process. To be successful, data science needs to be combined with domain knowledge within individual organizations.

When developing these solutions, a few R\&D challenges have been observed. For example:

- How can effective features be extracted from wind plant data to account for changing turbine operational conditions, aging processes, and complexity?

It is important to integrate AI models with physical understanding of the investigated problems. For certain failure modes, the R\&D opportunity lies in understanding the physical damage propagation process. A pertinent question to explore is:

- How may this understanding be integrated with these solutions to develop digital twins of turbines and plants?

The R\&D for AI frameworks should address feature extraction, ML models, actionable recommendations, and uncertainty. For example, ML models can include the development of surrogate models to approximate physical processes, definition of an error function, and deep reinforcement learning for perception. 


\section{Summary and Conclusions}

The information exchanged and new R\&D opportunities identified at the DRC workshops and meetings are valuable for prioritization of future R\&D plans. The DRC workshops and meetings provide a venue for exchange of information in an open and transparent manner, with the common goals of improvement in wind turbine drivetrain reliability and reduction in wind plant O\&M costs. The DRC also demonstrates how the industry may collaborate to close the gaps between design and manufacturing and field operational experience.

A few key takeaways are:

- There is strong support from the industry for continued drivetrain reliability R\&D. The current DOE-funded R\&D portfolio is investigating the most important drivetrain reliability issues as main bearing wear, gearbox bearing axial cracking, and many types of commonly observed pitch bearing reliability issues are not accounted for in design standards. Rating life or risk assessment methodologies are needed for these failure modes, along with development of mitigation strategies.

- Lubricants, materials, and surface engineering techniques-including lubricant type, viscosity grades, additive packages, coatings, and material cleanliness-have a significant impact on drivetrain component reliability.

- The research projects originally motivated by these reliability issues in land-based turbines are equally applicable to offshore turbines because the failure modes are similar. Naturally, O\&M cost impacts are even larger for offshore turbines, so further innovation in prognostics and health management, remote sensing and repairs, and maintenance strategies can significantly lower O\&M costs in offshore wind.

- Modeling that integrates physics and data domain methods is important to fully harness benefits of PHM technologies for wind and in support of component life extension.

- O\&M optimization can help drive cost further down through better understanding of the relationships between reliability and performance, handling of uncertainty, and consideration of logistics, especially for offshore wind. There are many R\&D opportunities related to AI solutions for wind including feature engineering, ML model development, uncertainty quantification, and decision making in support of both PHM and O\&M optimization for wind. 


\section{References}

Argonne National Laboratory. 2014. "Energy Systems 2014 Wind Turbine Tribology Seminar." Accessed July 30, 2021. https://www.anl.gov/es/energy-systems-2014-wind-turbine-tribologyseminar.

Becker, D., A. Gockel, T. Handreck, B. Lüneburg, T. Netz, and G. Volmer. 2017. "State-of-theart design process for pitch bearing applications of multi-MW wind turbine generators."

Presented at Conference for Wind Power Drives 2017.

Bertsche, B. 2008. Reliability in Automotive and Mechanical Engineering. Berlin, Germany: Springer-Verlag. doi: 10.1007/978-3-540-34282-3.

Brake, D. 2013. WTG SRB Main Bearing Failures (Presentation). Presented at UVIG Wind Turbine/Plant Operations \& Maintenance Users Group Meeting.

Brinji, O., K. Fallahnezhad, and P.A. Meehan. 2020. “Analytical Model for Predicting False Brinelling in Bearings.” Wear 444-445 (203135): doi: 10.1016/j.wear.2019.203135.

Carroll, J., A. McDonald, I. Dinwoodie, D. McMillan, M. Revie, and I. Lazakis. 2017. "Availability, Operation and Maintenance Costs of Offshore Wind Turbines with Different Drive Train Configurations.” Wind Energy 20 (2): 361-378. doi: 10.1002/we.2011.

Clark, C., G. Barter, K. Shaler, and B. DuPont. 2021. "Reliability-Based Layout Optimization in Offshore Wind Energy Systems.” Wind Energy. doi: 10.1002/we.2664.

Cunningham, Jr., J.S. and M.A. Morgan. 1979. "Review of Aircraft Bearing Rejection Criteria and Causes." Lubrication Engineering 35 (8): 435-441.

Daners, D. and V. Nickel. 2021. "More Torque is Better than Torque: Higher Torque Density for Gearboxes." Presented at Conference for Wind Power Drives 2021, Aachen, Germany, March 9$10,2021$.

Dao, C., B. Kazemtabrizi, and C. Crabtree. 2019. "Wind Turbine Reliability Data Review and Impacts on Levelised Cost of Energy." Wind Energy 22 (12): 1848-1871.

https://doi.org/10.1002/we.2404.

Dempsey, P. J. and S. Sheng. 2013. "Investigation of Data Fusion Applied to Health Monitoring of Wind Turbine Drivetrain Components." Wind Energy 16 (4): 479-489. doi: 10.1002/we.1512.

Desai, A., Y. Guo, S. Sheng, C. Phillips, and L. Williams. 2020. "Prognosis of Wind Turbine Gearbox Bearing Failures using SCADA and Modeled Data." Presented at the Prognostics and Health Management Conference of the PHM Society (virtual), Nov. 9-13, 2020, vol. 12, no. 1, p. 10. https://papers.phmsociety.org/index.php/phmconf/article/view/1292. 
Doner, S. 2020. "LCOE optimization in wind farms: How the digital gearbox can increase reliability and predict remaining useful lifetime for wind turbine drive trains." Presented at the Drivetrain Reliability Collaborative Meeting, Feb. 19, 2020. https://app.box.com/s/y133kpockvllf74pybh055gh7on4xga5.

Erdman, W. and J. Keller. 2016. "The DOE Next-Generation Drivetrain for Wind Turbine Applications: Gearbox, Generator, and Advanced Si/SiC Hybrid Inverter System: Preprint." (Conference Paper). NREL/CP-5000-66562. Golden, CO: National Renewable Energy Laboratory. https://www.nrel.gov/docs/fy16osti/66562.pdf.

Errichello, R. 2004. “Another Perspective: False Brinelling and Fretting Corrosion.” Tribology \& Lubrication Technology 60 (4): 34-36.

Errichello, R., J. Keller, S. Sheng, and A. Greco. 2012. Wind Turbine Tribology Seminar-A Recap (Technical Report). DOE/GO-102011-3496. Golden, CO: National Renewable Energy Laboratory. http://www.nrel.gov/docs/fy12osti/53754.pdf.

Evans, M.-H. 2016. "An Updated Review: White Etching Cracks (WECs) and Axial Cracks in Wind Turbine Gearbox Bearings.” Material Science and Technology 32 (11): 1133-1169. doi: $\underline{10.1080 / 02670836.2015 .1133022 .}$

Fischer, J. and P. Mönnig. 2019. Challenges for the Design Process of Pitch Bearings and the Contribution of Test Benches. Presented at Conference for Wind Power Drives 2019.

Gao, Z. and S. Sheng. 2018. "Real-Time Monitoring, Prognosis, and Resilient Control for Wind Turbine Systems.” Renewable Energy 116: 1-4. doi: 10.1016/j.renene.2017.10.059.

Gould, B., N. Demas, R. Erck, M. C. Lorenzo-Martin, O. Ajayi, and A. Greco. 2021. "The Effect of Electrical Current on Premature Failures and Microstructural Degradation in Bearing Steel." International Journal of Fatigue 145 (106078). doi: 10.1016/j.ijfatigue.2020.106078.

Gould, B., N.G. Demas, and A.C. Greco. 2019. "The Influence of Steel Microstructure and Inclusion Characteristics on the Formation of Premature Bearing Failures with Microstructural Alterations." Materials Science and Engineering: A 751: 237-245. doi: 10.1016/j.msea.2019.02.084.

Gould, B., N.G. Demas, G. Pollard, J.J. Rydel, M. Ingram, and A.C. Greco. 2019. "The Effect of Lubricant Composition on White Etching Crack Failures." Tribology Letters 67 (1): 7. doi: 10.1007/s11249-018-1106-y.

Gould, B. and A. Greco. 2015. "The Influence of Sliding and Contact Severity on the Generation of White Etching Cracks.” Tribology Letters 60 (29). doi: 10.1007/s11249-015-0602-6.

Gould, B. and A. Greco. 2016. "Investigating the Process of White Etching Crack Initiation in Bearing Steel.” Tribology Letters 62 (26). doi: 10.1007/s11249-016-0673-Z. 
Gould, B., A. Greco, K. Stadler, and X. Xiao. 2017. "An Analysis of Premature Cracking Associated with Microstructural Alterations in an AISI 52100 Failed Wind Turbine Bearing Using X-ray Tomography." Materials and Design 117: 417-429. doi:

10.1016/j.matdes.2016.12.089.

Gould, B., A. Greco, K. Stadler, E. Vegter, and X. Xiao. 2017. "Using Advanced Tomography Techniques to Investigate the Development of White Etching Cracks in a Prematurely Failed Field Bearing." Tribology International 116, 362-370. doi: 10.1016/j.triboint.2017.07.028.

Gould, B., M. Paladugu, N.G. Demas, A.C. Greco, and R.S. Hyde. 2019. "Figure the Impact of Steel Microstructure and Heat Treatment on the Formation of White Etching Cracks." Tribology International 134: 232-239. doi 10.1016/j.triboint.2019.02.003.

Grebe, M., J. Molter, F. Schwack, and G. Poll. 2018. "Damage Mechanisms in Pivoting Rolling Bearings and their Differentiation and Simulation." Bearing World Journal 3: 71-86. http://kth.diva-portal.org/smash/record.jsf?pid=diva2\%3A1433594\&dswid=6752.

Greco, A. 2014. "Reliability Improvement of Tribological Contacting Components." Presented at 2014 Wind Power Program Peer Review, March 24-27, 2014.

https://www.energy.gov/sites/prod/files/2014/06/f16/eere_wpp_2014_peer_review Reliabilityan dA2e.pdf.

Greco, A., S. Sheng, J. Keller, and A. Erdemir. 2013. "Material Wear and Fatigue in Wind Turbine Systems.” Wear 302: 1583-1591. doi: 10.1016/j.wear.2013.01.060.

Guo, Y., O. Bankestrom, R. Bergua, J. Keller, and M. Dunn. 2021. "Investigation of Main Bearing Operating Conditions in a Three-Point Mount Wind Turbine Drivetrain." Forschung im Ingenieurwesen. doi: 10.1007/s10010-021-00477-8.

Guo, Y. and J. Keller. 2018. "Investigation of High-Speed Shaft Bearing Loads in Wind Turbine Gearboxes through Dynamometer Testing." Wind Energy 21 (2): 139-50. doi: 10.1002/we.2150.

Guo, Y. and Keller, J. 2020. "Validation of Combined Analytical Methods to Predict Slip in Cylindrical Roller Bearings." Tribology International 148 (106347). doi:

$\underline{10.1016 / \text { j.triboint.2020.106347. }}$.

Guo, Y., J. Keller, W. LaCava. 2015. "Planetary Gear Load Sharing of Wind Turbine Drivetrains Subjected to Non-Torque Loads.” Wind Energy 18 (4): 757-768. doi: 10.1002/we.1731.

Guo, Y., J. Keller, and R. G. Parker. 2014. "Nonlinear Dynamics and Stability of Wind Turbine Planetary Gear Sets Under Gravity Effects." European Journal of Mechanics - A/Solids 47: 4557. doi: 10.1016/j.euromechsol.2014.02.013.

Guo, Y. and J. Keller. 2020. "Validation of a Generalized Formulation for Load-Sharing Behavior in Epicyclic Gears for Wind Turbines: Preprint." (Conference Paper). NREL/CP-500076380. Golden, CO: National Renewable Energy Laboratory. https://www.nrel.gov/docs/fy20osti/76380.pdf. 
Guo, Y., S. Lambert, R. Wallen, R. Errichello, and J. Keller. 2016. "Theoretical and Experimental Study on Gear-coupling Contact and Loads Considering Misalignment, Torque, and Friction Influences." Mechanism and Machine Theory 98: 242-262. doi: 10.1016/j.mechmachtheory.2015.11.015.

Guo, Y., S. Sheng, C. Phillips, J. Keller, P. Veers, and L. Williams. 2020. "A Methodology for Reliability Assessment and Prognosis of Bearing Axial Cracking in Wind Turbine Gearboxes." Renewable and Sustainable Energy Reviews 127 (109888). doi: 10.1016/j.rser.2020.109888.

Han, J.W., J.S. Nam, Y.J. Park, G.H. Lee, and Y.Y. Nam. 2015. "An Experimental Study on the Performance and Fatigue Life of Pitch Bearing for Wind Turbine." Journal of Mechanical Science Technology 29 (5): 1963-1971. doi: 10.1007/s12206-015-0417-2.

Harris, T., J.H. Rumbarger, and C.P. Butterfield. 2009. Wind Turbine Design Guideline DG03: Yaw and Pitch Rolling Bearing Life (Technical Report). NREL/TP-500-42362. Golden, CO: National Renewable Energy Laboratory. https://www.nrel.gov/docs/fy10osti/42362.pdf.

Hart, E., B. Clarke, G. Nicholas, A. Kazemi Amiri, J. Stirling, J. Carroll, R. Dwyer-Joyce, A. McDonald, and H. Long. 2020. "A Review of Wind Turbine Main Bearings: Design, Operation, Modelling, Damage Mechanisms and Fault Detection." Wind Energy Science 5: 105-124. doi: 10.5194/wes-5-105-2020.

Hart, E., A. Turnbull, J. Feuchtwang, D. McMillan, E. Golysheva, and R. Elliott. 2019. "Wind Turbine Main-bearing Loading and Wind Field Characteristics." Wind Energy 22 (11): 15341547. doi: $10.1002 /$ we. 2386.

Helsen, J., Y. Guo, and J. Keller. 2018. "Gearbox High-Speed-Stage Bearing Slip Induced by Electric Excitation in a Test Facility." Wind Energy 21 (11): 1191-1201. doi: 10.1002/we.2223.

Helsen, J., Y. Guo, J. Keller, and P. Guillaume. 2016. "Experimental Investigation of Bearing Slip in a Wind Turbine Gearbox During a Transient Grid Loss Event." Wind Energy 19 (12): 2255-2269. doi: 10.1002/we.1979.

Hong, L., J. S. Dhupia, and S. Sheng. 2014. "Explanation of Frequency Features Enabling Detection of Faults in Equally Spaced Planetary Gearbox." Mechanism and Machine Theory 73: 169-183. doi: 10.1016/j.mechmachtheory.2013.10.014.

Hong, L., Y. Qu, J. S. Dhupia, S. Sheng, Y. Tan, and Z. Zhou. 2017. “A Novel Vibration-Based Fault Diagnostic Algorithm for Gearboxes Under Speed Fluctuations Without Rotational Speed Measurement." Mechanical Systems and Signal Processing 94: 14-32. doi: 10.1016/j.ymssp.2017.02.024.

Hornemann, M. 2019. “Top Failure Observations from the Field.” Presented at Drivetrain Reliability Collaborative Meeting, February 20, 2019. https://app.box.com/s/7vo2ssy085raoeqa8wnyh5lrfjne6lgs.

Houpert, L. 1999. "Bearing Life Calculation in Oscillatory Applications.” Tribology Transactions 42 (1): 136-143. doi: 10.1080/10402009908982200. 
International Organization for Standardization. 2021. "The Different Types of ISO Publications." Accessed July 30, 2021. https://www.iso.org/deliverables-all.html.

Jensen, O. L., L. Heuser, and K. E. Petersen. 2021. "Prevention of 'White Etching Cracks' in Rolling Bearings in Vestas Wind Turbines.” Presented at Conference for Wind Power Drives 2021.

Keller, J. 2014. “Gearbox Reliability Collaborative.” Presented at 2014 Wind Power Program Peer Review, March 24-27, 2014.

https://www.energy.gov/sites/prod/files/2014/06/f16/eere_wpp_2014_peer_review_Reliabilityan dA2e.pdf.

Keller, J. 2017. Drivetrain Reliability (Collaboratives, Monitoring, and O\&M). https://www.energy.gov/sites/prod/files/2018/02/f48/Wind-Energy-Technologies-Office-PeerReview-R\%26D.pdf.

Keller, J. 2019. Wind Turbine Drivetrain Reliability. https://www.energy.gov/sites/prod/files/2019/05/f62/NREL-T15-Keller_FINAL.pdf.

Keller, J., B. Gould, and A. Greco. 2017. Investigation of Bearing Axial Cracking: Benchtop and Full-Scale Test Results (Technical Report). NREL/TP-5000-67523. Golden, CO: National Renewable Energy Laboratory. http://www.nrel.gov/docs/fy17osti/67523.pdf.

Keller, J., Y. Guo, Z. Zhang, and D. Lucas. 2018. "Comparison of planetary bearing load-sharing characteristics in wind turbine gearboxes." Wind Energy Science 3: 947-960, doi: 10.5194/wes3-947-2018.

Keller, J., S. Sheng, J. Cotrell, and A. Greco. 2016. Wind Turbine Drivetrain Reliability Collaborative Workshop: A Recap (Technical Report). DOE/GO-102016-4878. Golden, CO: National Renewable Energy Laboratory. http://www.nrel.gov/docs/fy16osti/66593.pdf.

Keller, J. and R. Wallen. 2015. Gearbox Reliability Collaborative Phase 3 Gearbox 2 Test Report (Technical Report). NREL/TP-5000-63693, Golden, CO: National Renewable Energy Laboratory. doi: $10.7799 / 1254154$.

Keller, J. and R. Wallen. 2017. Gearbox Reliability Collaborative Phase 3 Gearbox 3 Test Report (Technical Report). NREL/TP-5000-67612. Golden, CO: National Renewable Energy Laboratory. doi: $\underline{10.7799 / 1337868}$.

Kotzalas, M.N. and G.L. Doll. 2010. "Tribological Advancements for Reliable Wind Turbine Performance." Philosophical Transactions of the Royal Society A 368: 4829-4850. doi: $\underline{10.1098 / \text { rsta.2010.0194. }}$

LaCava, W., Y. Xing, C. Marks, Y. Guo, and T. Moan. 2013. "Three-Dimensional Bearing Load Share Behaviour in the Planetary Stage of a Wind Turbine Gearbox." IET Renewable Power Generation 7 (4): 359-369. doi: 10.1049/iet-rpg.2012.0274. 
Lantz, E. 2013. Operations Expenditures: Historical Trends and Continuing Challenges (Presentation). NREL/TP-5000-58606. Golden, CO: National Renewable Energy Laboratory. http://www.nrel.gov/docs/fy13osti/58606.pdf.

Lee, J. and F. Zhao. 2020. Global Wind Report 2019 (Report). Brussels, Belgium: Global Wind Energy Council. https://gwec.net/download/118362/.

J. Lee, J., M. Ghaffari, and S. Elmeligy. 2011. "Self-maintenance and Engineering Immune Systems: Towards Smarter Machines and Manufacturing Systems." Annual Reviews in Control 35 (1): 111-122. doi: 10.1016/j.arcontrol.2011.03.007.

Leung, J. F.W., R. Voothaluru, R. W. Neu. 2021. "Predicting White Etching Matter Formation in Bearing Steels using a Fretting Damage Parameter." Tribology International 159 (106966). doi: $\underline{10.1016 / \text { j.triboint.2021.106966. }}$.

López-Uruñuela, F.J., B. Fernández-Díaz, F. Pagano, A. López-Ortega, B. Pinedo, R. Bayón, J. Aguirrebeitia. 2021. "Broad Review of "White Etching Crack" Failure in Wind Turbine Gearbox Bearings: Main Factors and Experimental Investigations." International Journal of Fatigue 145 (106091). doi: 10.1016/j.ijfatigue.2020.106091.

Lucas, D. 2019. "How to Choose the Right Bearings for Offshore Wind Turbines." Windpower Engineering and Development 42-45.

Manieri. F., K. Stadler, G.E. Morales-Espejel, and A. Kadiric A. 2019. "The Origins of White Etching Cracks and their Significance to Rolling Bearing Failures." International Journal of Fatigue 120: 107-33. doi: S0301-679X(20)30187-0/sb10.

Mauricio, A., S. Sheng, and K. Gryllias. 2020. "Condition Monitoring of Wind Turbine Planetary Gearboxes Under Different Operating Conditions. Paper No. GTP-19-1317.” Journal of Engineering for Gas Turbines and Power 142 (3): 031003. doi: 10.1115/1.4044683.

McGuire, N. 2021. "Greases for Slow and Steady Wind Turbine Bearings." Tribology \& Lubrication Technology 42-53.

Menck, O., M. Stammler, and F. Schleich. 2020. "Fatigue Lifetime Calculation of Wind Turbine Blade Bearings Considering Blade-dependent Load Distribution." Wind Energy Science 5: 17431754. doi: $10.5194 /$ wes-5-1743-2020.

Natarajan, A., D. Remigius, Y. Guo, and J. Keller. 2021. "A Proposed Criteria to Identify Wind Turbine Drivetrain Bearing Loads that Induce Roller-Slip-Based White-Etching Cracks." Forschung im Ingenieurwesen. doi: 10.1007/s10010-021-00473-y.

National Renewable Energy Laboratory. 2021. "DRC Meeting Presentation Archive." Accessed July 30, 2021. https://app.box.com/s/095z4ly60gvwrxv71hbg32skwrjk1q9q. 
Nejad, A. R., J. Keller, Y. Guo, S. Sheng, H. Polinder, S. Watson, J. Dong, Z. Qin, A. Ebrahimi, R. Schelenz, F. G. Guzmán, D. Cornel, R. Golafshan, G. Jacobs, B. Blockmans, J. Bosmans, B. Pluymers, J. Carroll, S. Koukoura, E. Hart, A. McDonald, A. Natarajan, J. Torsvik, F. K. Moghadam, P.-J. Daems, T. Verstraeten, C. Peeters, and J. Helsen. 2021. "Wind Turbine Drivetrains: State-of-the-art Technologies and Future Development Trends." Wind Energy Science Discussions. [preprint], https://doi.org/10.5194/wes-2021-63, in review.

Orozco, R., S. Sheng, and C. Phillips. 2018. "Diagnostic Models for Wind Turbine Gearbox Components Using SCADA Time Series Data." Presented at IEEE International Conference on Prognostics and Health Management, June 11-13, 2018, pp. 1-9.

Pfaffel, S., S. Faulstich, and S. Sheng. 2019. "Recommended Key Performance Indicators for Operational Management of Wind Turbines." Journal of Physics: Conference Series 1356: 012040. doi: 10.1088/1742-6596/1356/1/012040.

Reininga, A. 2020. "The full circle of gearbox bearing performance." Presented at the Drivetrain Reliability Collaborative Meeting, Feb. 19, 2020. https://app.box.com/s/bfb9x0sn2ka3mbszhtzip456j64oawjx.

Rinaldi, G., P. R. Thies, and L. Johanning. 2021. "Current Status and Future Trends in the Operation and Maintenance of Offshore Wind Turbines: A Review." Energies 14 (9): 2484. doi: $\underline{10.3390 / \text { en } 14092484 .}$

Rolink, A., G. Jacobs, T. Schröder, D. Keller, T. Jakobs, D. Bosse, J. Lang, and G. Knoll. 2021. "Methodology for the Systematic Design of Conical Plain Bearings for use as Main Bearings in Wind Turbines." Forshung im Ingenieurwesen. doi: 10.1007/s10010-021-00452-3.

Roy, S., B. Gould, Y. Zhou, N. G. Demas, A. C. Greco, and S. Sundararajan. 2019. "Effect of Retained Austenite on White Etching Crack Behavior of Carburized AISI 8620 Steel Under Boundary Lubrication.” Tribology Letters 67 (40): 9. doi: 10.1007/s11249-019-1153-z.

Ščepanskis, M., B. Gould, and A. Greco. 2017. "Empirical Investigation of Electricity SelfGeneration in a Lubricated Sliding-Rolling Contact." Tribology Letters 65 (109): 10. doi: 10.1007/s11249-017-0892-y.

Schwack, F., N. Bader, J. Leckner, C. Demaille, and G. Poll. 2020. “A Study of Grease Lubricants under Wind Turbine Pitch Bearing Conditions." Wear 454-455 (203335). doi: 10.1016/j.wear.2020.203335.

Schwack, F., F. Prigge, and G. Poll. 2018. "Finite Element Simulation and Experimental Analysis of False Brinelling and Fretting Corrosion." Tribology International 126: 352-362. doi: 10.1016/j.triboint.2018.05.013.

Sethuraman, L., Y. Guo, S. Sheng. 2015. "Mitigation of Micropitting in Wind Turbine Main Shaft Bearings." WindTech International. https://www.windtech-international.com/editorialfeatures/features/articles/mitigation-of-micropitting-in-wind-turbine-main-shaft-bearings. 
Sheng, S. 2010. Wind Turbine Micropitting Workshop: A Recap (Technical Report). NREL/TP500- 46572. Golden, CO: National Renewable Energy Laboratory.

http://www.nrel.gov/docs/fy10osti/46572.pdf.

Sheng, S. 2014a. "Gearbox Failure Database, Condition Monitoring, and Operation \&

Maintenance Research." Presented at 2014 Wind Power Program Peer Review, March 24-27, 2014.

https://www.energy.gov/sites/prod/files/2014/06/f16/eere wpp 2014 peer review Reliabilityan dA2e.pdf.

Sheng, S. 2014b. "Editorial: Wind Turbine Condition Monitoring." Wind Energy 17 (5): 671672. doi: $\underline{10.1002 / \text { we. } 1725 .}$.

Sheng, S. 2014c. Wind Turbine Gearbox Condition Monitoring Vibration Analysis Benchmarking Datasets (Data). NREL/DA-5000-61779. Golden, CO: National Renewable Energy Laboratory.

Sheng, S. 2016. "Monitoring of Wind Turbine Gearbox Condition through Oil and Wear Debris Analysis: A Full-Scale Testing Perspective.” Tribology Transactions 59 (1): 149-162. doi: $\underline{10.1080 / 10402004.2015 .1055621 .}$.

Sheng, S. and Y. Guo. 2019. "A Prognostics and Health Management Framework for Wind." Proceedings of the ASME Turbo Expo 2019: Turbomachinery Technical Conference and Exposition. Volume 9: Oil and Gas Applications; Supercritical CO2 Power Cycles; Wind Energy. Phoenix, AZ. June 17-21, 2019. V009T48A013. American Society of Mechanical Engineers. doi: 10.1115/GT2019-91533.

Sheng, S. and D. Roberts. 2017. "Improving the Analysis of Gear-Oil Debris with a Compact Filter." Windpower Engineering \& Development 9: 44-46.

https://www.windpowerengineering.com/dw-sync/improving-analysis-gear-oil-debris-compactfilter.

SKF. 2021. "SKF RecondOil.” Accessed September 14, 2021. https://www.skf.com/us/services/recondoil.

Song, W. and A. K. Karikari-Boateng. 2021. Enhanced Test Strategy of Pitch Bearing Based on Detailed Motion Profile. Presented at Conference for Wind Power Drives 2021.

Stammler, M., A. Reuter, and G. Poll. 2018. "Cycle Counting of Roller Bearing Oscillations Case Study of Wind Turbine Individual Pitching System." Renewable Energy Focus 25: 40-47. doi: $10.1016 /$ j.ref.2018.02.004.

Stammler, M., P. Thomas, A. Reuter, F. Schwack, and G. Poll. 2020. "Effect of Load Reduction Mechanisms on Loads and Blade Bearing Movements of Wind Turbines." Wind Energy 23: 274290. doi: $\underline{10.1002 / \text { we. } 2428}$. 
Stehly, T., P. Beiter, and P. Duffy. 2020. 2019 Cost of Wind Energy Review. NREL/TP-500078471. Golden, CO: National Renewable Energy Laboratory. https://www.nrel.gov/docs/fy21osti/78471.pdf.

Stirling, J., E. Hart, and A. Kazemi Amiri. 2021. "Constructing Fast and Representative Analytical Models of Wind Turbine Main Bearings." Wind Energy Science 6: 15-31. doi: 10.5194/wes-6-15-2021.

Tamilselvan, P., P. Wang, S. Sheng, and J. M. Twomey. 2013. "Two-Stage Diagnosis Framework for Wind Turbine Gearbox Condition Monitoring." International Journal of Prognostics and Health Management 4 (SP2). doi: 10.36001/ijphm.2013.v4i3.2140.

U.S. Department of Energy. 2015. Wind Vision: A New Era for Wind Power in the United States (Technical Report). DOE/GO-102015-4557. Washington, D.C.: U.S. Department of Energy. https://doi.org/10.2172/1220428.

U.S. Department of Energy. 2020. Wind Energy Technologies Office Multi-Year Program Plan Fiscal Years 2021-2025 (Technical Report). DOE/GO-102020-5486. Washington, D.C.: U.S. Department of Energy. https://www.osti.gov/biblio/1760301-wind-energy-technologies-officemulti-year-program-plan-fiscal-years.

U.S. Department of Energy. 2021. "Artificial Intelligence and Machine Learning." Accessed July 30, 2021. https://www.energy.gov/science/initiatives/artificial-intelligence-and-machinelearning.

Vaes, D., P. Clement, and U. Lindstedt. 2021. "Roller Bearings for the Next Generation of Wind Gearboxes." Presented at Conference for Wind Power Drives 2021, Aachen, Germany, March 9 10, 2021.

Vaes, D., Y. Guo, P. Tesini, and J. Keller. 2019. Investigation of Roller Sliding in Wind Turbine Gearbox High-Speed-Shaft Bearings (Technical Report). NREL/TP-5000-73286. Golden, CO: National Renewable Energy Laboratory. https://www.nrel.gov/docs/fy19osti/73286.pdf.

Veers, P., S. Sheng, J. Keller, and Y. Guo. 2018. Turbine Life Prediction and Reliability: Design and Operation (Presentation). Presented at IEA TEM \#93, December 13, 2018. NREL/PR-500073023. Golden, CO: National Renewable Energy Laboratory. https://www.nrel.gov/docs/fy19osti/73023.pdf.

Verstraeten, T., A. Nowe, J. Keller, Y. Guo, S. Sheng, and J. Helsen. 2019. "Fleetwide DataEnabled Reliability Improvement of Wind Turbines." Renewable \& Sustainable Energy Reviews 109: 428-437. doi: 10.1016/j.rser.2019.03.019.

Weber, A. and A. Hansen. 2021. "Focus Areas in Vestas Powertrain." Presented at Conference for Wind Power Drives 2021, Aachen, Germany, March 9-10, 2021. 
Williams, L., C. Phillips, S. Sheng, A. Dobos, and X. Wei. 2020. "Scalable Wind Turbine Generator Bearing Fault Prediction Using Machine Learning: A Case Study." Presented at IEEE International Conference on Prognostics and Health Management, Detroit, MI, pp. 1-9. doi: 10.1109/ICPHM49022.2020.9187050.

Winergy. 2021. "High density gearboxes.” Accessed July 30, 2021. https://www.winergygroup.com/en/Products/Gear-Units/High-Density/p/HighDensityX.

Wiser, R., M. Bolinger, and E. Lantz. 2019. "Assessing Wind Power Operating Costs in the United States: Results from a Survey of Wind Industry Experts." Renewable Energy Focus 30: 46-57. doi: 10.1016/j.ref.2019.05.003.

Wöll, L., G. Jacobs, and A. Kramer. 2018. "Lifetime Calculation of Irregularly Oscillating Bearings in Offshore Winches." Modeling, Identification and Control 39 (2): 61-72. doi: 10.4173/mic.2018.2.2.

Yampikulsakul, N., E. Byon, S. Huang, S. Sheng, and M. You. 2014. "Condition Monitoring of Wind Power System with Nonparametric Regression Analysis." IEEE Transactions on Energy Conversion 29 (2): 288-299. doi: 10.1109/TEC.2013.2295301.

Yan, R., X. Chen, W. Li, and S. Sheng. 2014. "Editorial: Mathematical Methods and Modeling in Machine Fault Diagnosis. Article ID 516590." Mathematical Problems in Engineering 2014. doi: $10.1155 / 2014 / 516590$.

Yang, W., S. Sheng, and R. Court. 2013. "Operational-Condition-Independent Criteria Dedicated to Monitoring Wind Turbine Generators." International Journal of Prognostics and Health Management 4 (SP2). doi: 10.36001/ijphm.2013.v4i3.2133.

Zappala, D., P. J. Tavner, C. J. Crabtree, and S. Sheng. 2014. "Side-Band Algorithm for Automatic Wind Turbine Gearbox Fault Detection and Diagnosis." IET Renewable Power Generation 8 (4): 380-389. doi: 10.1049/iet-rpg.2013.0177.

Zaretsky, E.V. and Branzai, E.V. 2017. Rolling-Bearing Service Life Based on Probable Cause for Removal-A Tutorial (Technical Report). NASA/TM-2017-219545. Cleveland, OH: Glenn Research Center. https://ntrs.nasa.gov/archive/nasa/casi.ntrs.nasa.gov/20170009563.pdf.

Zeichfüß1, R., A. Jöckel, M. Deicke, D. Daners, and C. Fox. 2021. "Integrated 3-Stage Planetary Gearbox With Oil-Cooled Generator." Presented at Conference for Wind Power Drives 2021, Aachen, Germany, March 9-10, 2021.

ZF. 2021. "SHIFT modular gearbox platforms.” Accessed July 30, 2021. https://www.zf.com/products/media/industrial/wind/SHIFTx platform 2021 online.pdf. 